\title{
Hard to digest-bowel perforation due to a swallowed toothpick
}

\author{
Gokce Kaan Atac ${ }^{1}$, Salih Erpulat Ozıs ${ }^{2}$ \\ 1. Department of Radiology, Ufuk University Medical School, Ankara, Turkey. 2. Department of Surgery, Ufuk University \\ Medical School, Ankara, Turkey.
}

Correspondence: Gokce Kaan Atac, Assistant Professor. Address: Department of Radiology, Ufuk University Medical School, Konya yolu No: 86-88. 06520, Balgat-Ankara, Turkey. Email: gk.atac@ufuk.edu.tr

Received: February 26, 2014

Accepted: March 31, $2014 \quad$ Online Published: April 15, 2014

DOI : $10.5430 /$ ijdi.v1n2p43

URL: http://dx.doi.org/10.5430/ijdi.v1n2p43

\begin{abstract}
Acute right lower quadrant pain is one of the most frequent reasons for emergency calls. Acute appendicitis is also the most abundant surgical intervention due to acute abdominal pain. Foreign body ingestion is another but rare cause of acute abdominal pain especially in adult patients. We describe the clinical, surgical and multidetector computed tomography imaging findings of large bowel perforation due to unintentionally ingested wooden toothpick.
\end{abstract}

\section{Keywords}

Large Bowel, Perforation, Wooden toothpick, MDCT

\section{I ntroduction}

Bowel wall perforation may occur secondary to different types of foreign body ingestion. Fish bones or metallic dental devices or their parts are more frequently reported as a culprit. Children, mentally ill persons, people who have a tendency to commit suicide are more prone to have bowel wall perforations due to ingestion of these objects. Foreign bodies may pass by without feeling them if dentures covering the palate ${ }^{[1-7]}$. Bowel wall perforations due to toothpicks reported before in different ages causing even causing liver injuries and abscesses ${ }^{[8-10]}$. Management of these injuries requires emergent surgical intervention and not easy to anticipate the exact cause of abdominal catastrophy in the beginning. Laparoscopic treatment of perforations was described but exploration abdominal cavity by open surgery may be safe to discover the exact location of perforation ${ }^{[8]}$.

\section{Case report}

Fifty year old man was seen on emergency department for nausea and right lower quadrant pain. Tenderness with deep compression was found by physical examination.

Routine blood analysis revealed blood cell counts in normal range. Abdominal radiography did not show significant findings. Abdominal ultrasound was insufficient to explore the appendix inflammation since bowel gas was overlaying the deep structures of right lower quadrant against persistent compression with probe to displace them. Abdominal computed 
tomography (CT) was performed 10 hours after admission since he felt more pain and white cell count was increased. Sixteen row multidetector CT examination of the abdomen was performed before and after intravenous contrast media injection (Xenetix 300/100, Guerbet, France) with drinking of 1.5 liters of water stained by iodinated contrast material (Urografin $50 \mathrm{ml}$, Schering, Germany). Caecal wall thickening and luminal narrowing due to edema and tiny linear opacity of roughly 5 centimeters long located vertically in the lumen were seen on axial and reformatted sagittal images. Small part of the linear opacity was noticed perforated the anterior wall of caecum and extended into the fluid like density mass ( 30 HU with CT) next to caecum (see Figure 1a, 1b). Appendix vermiformis was 6 millimeters in diameter looked full of iodinated water without an appendicolith. Patient was not using artificial denture and recalled any ingestion of foreign material or recent dinning fish or chicken.

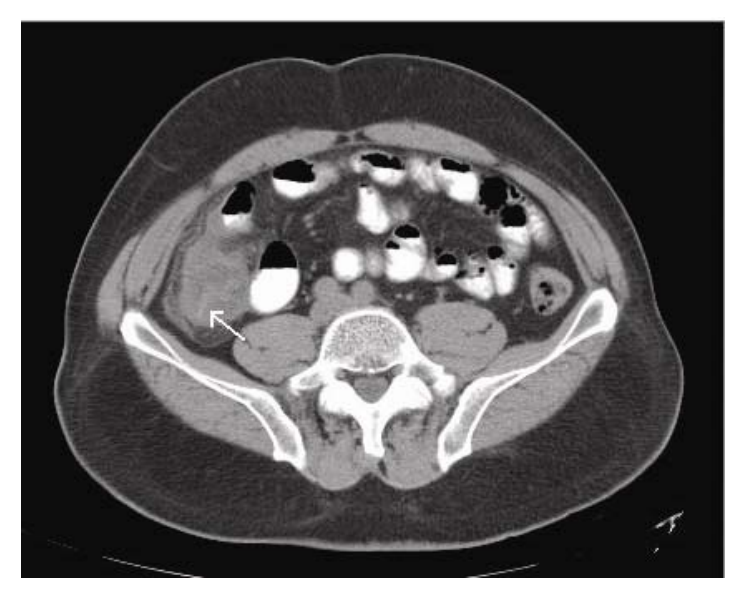

Figure 1a. Axial CT images of the lower abdomen showing pericaecal fluid collection and white linear density of toothpick inside the large bowel lumen (white arrow).

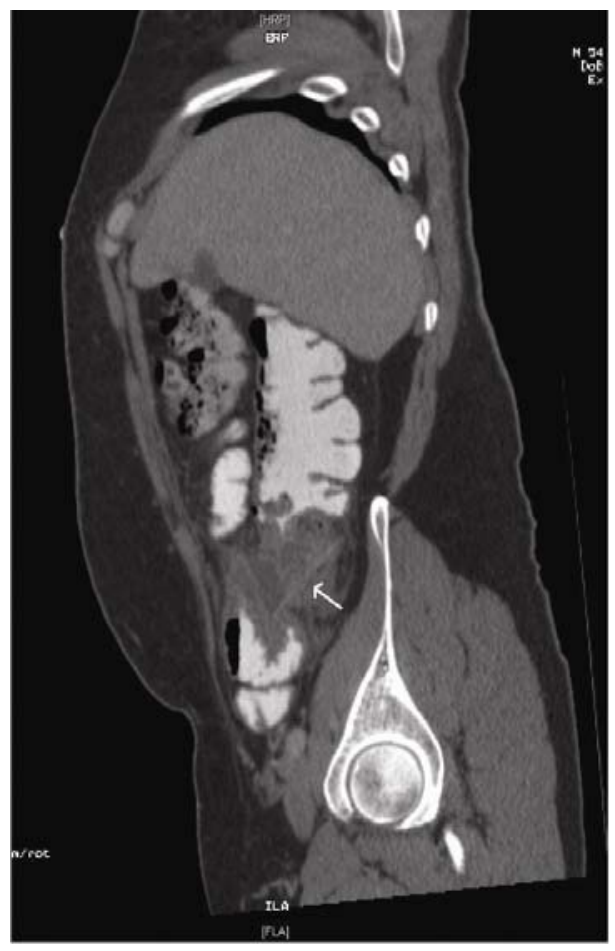

Figure 1b. Oblique sagittal reformatted CT image of ascending colon and caecum. Inferior end of the vertical linear density of toothpick is perforated the anterior wall and reaching the fluid density around the bowel wall (white arrow). 
Patient was taken to operating room for suspected plastron appendicitis. Caecal perforation with a toothpick was seen after McBurney incision exposure of the caecum of large bowel (see Figure 2).

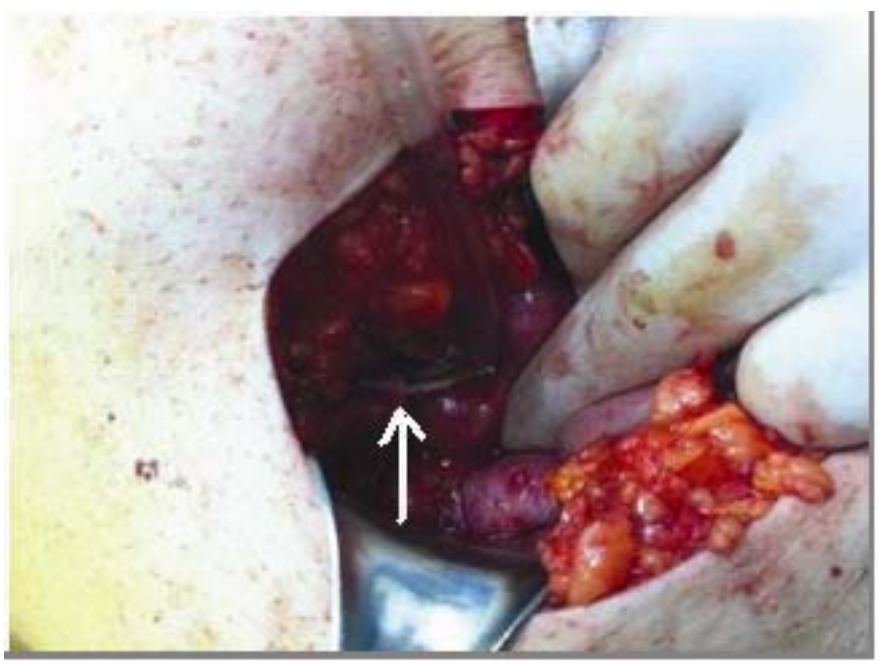

Figure 2. Intraoperative picture of caecum is showing a toothpick (white line) extending out of the lumen through the anterior bowel wall.

The toothpick was gently removed from the colonic wall and perforation was closed with 00 vicryl sutures. Peritoneal cavity has been lavaged with saline solution and a suction drain was placed from the perforation area to the rectovesical excavation. Routine abdominal closure was performed. The recovery period was uneventful.

\section{Discussion}

Ingestion of the foreign bodies may occur intentionally or without notice. Various kinds of objects were reported mostly swallowed by mentally retarded children. Foreign bodies most commonly pass through the lumen and surgical intervention is not a frequent procedure. Even perforation of the bowel wall may be managed conservatively. Endoscopic removal of them may also be performed. Granulomatous reaction of the bowel wall mimicking inflammatory bowel disease induced by delayed harmful effect may occur besides the acute perforation ${ }^{[1,3,4]}$.

$\mathrm{CT}$ is the most frequent imaging tool for acute abdomen that may reveal the early findings of bowel damage. Gas and iodinated contrast material out of the bowel lumen are the most reliable direct findings while bowel wall thickening and bowel wall defects are indirect CT signs that may support the diagnosis. Stranding of fat tissue around the inflamed bowel part may also direct the attention to the diseased segment. Axial and multiplanar reformatted CT images in sagittal or coronal planes may show the anatomic details of the abdomen in a very fast manner by multidetector CT technique. Iatrogenic or traumatic injuries including foreign body ingestion, inflammatory, ischemic or neoplastic disorders may show similar findings. Water with iodinated contrast material instead of containing barium should be preferred for intestinal staining due to strong irritational potential of the barium on peritoneum in case of leakage through the perforation or rupture of the bowel wall. Adjustment of display window and center to visualize the different densities like air and foreign subjects between the high density bowel loops should be done ${ }^{[2,5,6]}$.

High density objects like metallic pieces, bones of chicken or fish may produce high contrast with surrounding soft tissue and facilitates the detection. It would be challenging to distinguish low density foreign bodies in between the surrounding soft tissues of intrabdominal structures. CT has a unique capacity to show them since all pixels produced in a cross sectional picture is created from numbers representing relative attenuation of relevant part of the tissue from $0.5 \mathrm{~mm}$ thin collimated $\mathrm{x}$ ray beams. 
In conclusion, even if the complications and diagnosis was reported before in the literature for perforation of bowel wall with ingested foreign material, it is a rare and life threatening surgical emergency today, Perforation of bowel wall with an ingestion of a wooden toothpick is a serious problem which is hard to anticipate in an adult person without any other mental or dental problems. Multidetector CT is a helpful tool to diagnose the foreign body with a skeptical evaluation of the axial cross sectional and reformatted images.

\section{References}

[1] Li Voti G, Di Pace MR, Castagnetti M, De Grazia E, Cataliotti F. Needle Perforation of the Bowel in Childhood. J Pediatr Surg. 2004; 39: 231-232. http://dx.doi.org/10.1016/j.jpedsurg.2003.10.017

[2] Zissin R, Hertz M, Osadchy A, Even-Sapir E, Gayer G. Abdominal CT findings in nontraumatic colorectal perforation. EJR. 2008; 65:125-132. http://dx.doi.org/10.1016/j.ejrad.2007.03.014

[3] Ward MA, Tews MC. Small bowel perforation secondary to fish bone ingestion managed non-operatively. J Emerg Med. 2010; 1-4. http://dx.doi.org/10.1016/j.jemermed.2010.05.039

[4] Webster PJ, Peckham-Cooper A, Lansdown M. Small bowel perforation secondary to accidental dental plate ingestion. Int J Surg Case Rep. 2011; 2; 218-220. http://dx.doi.org/10.1016/j.ijscr.2011.07.003

[5] Noh CM, Chew FS. Small-Bowel Perforation by a Foreign Body. AJR. 1998; 171: 1002. http://dx.doi.org/10.2214/ajr.171.4.9762984

[6] Zissin R, Osadchy A, Gayer G. Abdominal CT findings in small bowel perforation. BJR. 2009: 82;162-171. http://dx.doi.org/10.1259/bjr/78772574

[7] Liu HJ, Liang CH, Huang B, Xie SF, Wang GY. Migration of a swallowed toothpick into the liver: the value of multiplanar CT. BJR. 2009; 82: e79-81. http://dx.doi.org/10.1259/bjr/16399296

[8] Witchmann MV, Hüttl MP, Billing A, Jauch KV. Laparoscopic management of small bowel perforation caused by a toothpick. Surg Endosc. 2004; 18: 717-718. http://dx.doi.org/10.1007/s00464-003-4267-0

[9] Ragazzi M, Delcò F, Rodoni-Cassis P, Brenna M, Lavanchy L, Bianchetti MG. Toothpick ingestion causing duodenal perforation. PediatrEmerg Care. 2010; 26: 506-507. http://dx.doi.org/10.1097/PEC.0b013e3181e5bf85

[10] Atila K, Güler S, Bora S, Gülay H. An unusual cause of small bowel perforation: apricot pit. Ulus Travma Acil Cerrahi Derg. 2011; 17: 286-288. http://dx.doi.org/10.5505/tjtes.2011.71676 